\title{
The Acute Toxicity of Copper to Gammarus fasciatus Say, A Freshwater Amphipod
}

\author{
Robert D. Judy, Jr. ${ }^{1}$ \\ Colorado State University, Ft. Collins, Colo., Research Conducted at \\ University of Michigan Biological Station, Pellston, Mich., \\ 1Present address: Biology Department, North Texas State University, Denton, Tex. 76203
}

The purpose of this toxicity test was to determine the reliability and comparability of Cu+t toxicity on Gammarus fasciatus. The study was conducted to compare toxicity $\overline{r e s u l t s ~ f o r ~ R a i n b o w ~ t r o u t, ~ S a l m o ~ g a i r d n e r i ~}$ Richardson, another coldwater poikilotherm. Since G. fasciatus comprises a major portion of the diet of many freshwater fishes, it can be stated to be an "important" species (PATRICK et al. 1968).

\section{MATERIALS AND METHODS}

G. fasciatus, a freshwater amphipod, was tested for its acute response to toxicity of $\mathrm{Cu}++$. It is an important food web organism comprising greater than $10 \%$ of the diet of trout, coldwater poikilotherms, and warmwater fishes (GECKLER et a1. 1976). G. fasciatus is found in wide distribution along with $G$. innaeus, Smith and Crangonyx gracilus, Smith. They are the majority of amphipods taken (PENNAK 1953). These organisms are widely distributed and are found in many habitat types from cold to warm waters (PENNAK 1953).

A standard screening bioassay in hard water was run to determine the range for the definitive tests (STANDARD METHODS 1965). Two definitive tests of $48 \mathrm{hr}$ duration were conducted to determine reproducibility and reliability of the test organism. Also, $48 \mathrm{hr}$ LC50 values were calculated to determine the response of $G$. fasciatus to Cut+ as CuSo 4 : Results of these tests were evaluated using the Litchfield and Wilcoxin Nomograph Analysis (LITCHFIELD and WILCOXIN 1949) for $\alpha=0.05$ confidence limits on the slope and LC50 values obtained.

A screening test using a control group and dilutions of $1.0,10.0,100$, and $1000 \mathrm{ppm}$ for Cu+t was used to determine broad range toxicity to $G$. fasciatus. Each battery jar was acid rinsed and contained 3.0I of solution and 10 test organisms picked randomly from a stock group. The organisms were collected from a cold spring near Alanson, Michigan on state highway M3I. The temperature of the spring ranged from 12 to $14^{\circ} \mathrm{C}$ and the organisms were transported back to the laboratory where they were kept for $48 \mathrm{hr}$ without feeding prior to testing. 


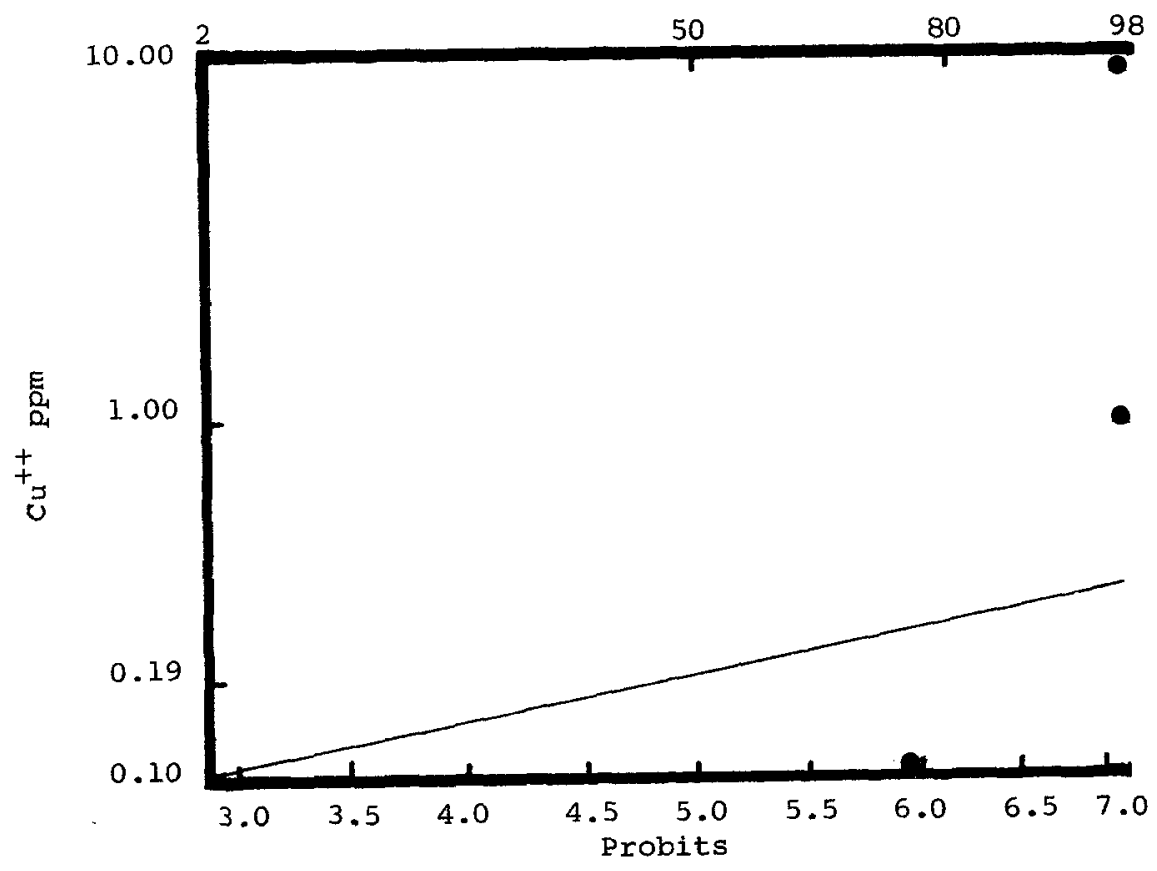

Fig. 1. Preliminary LC50 Determination

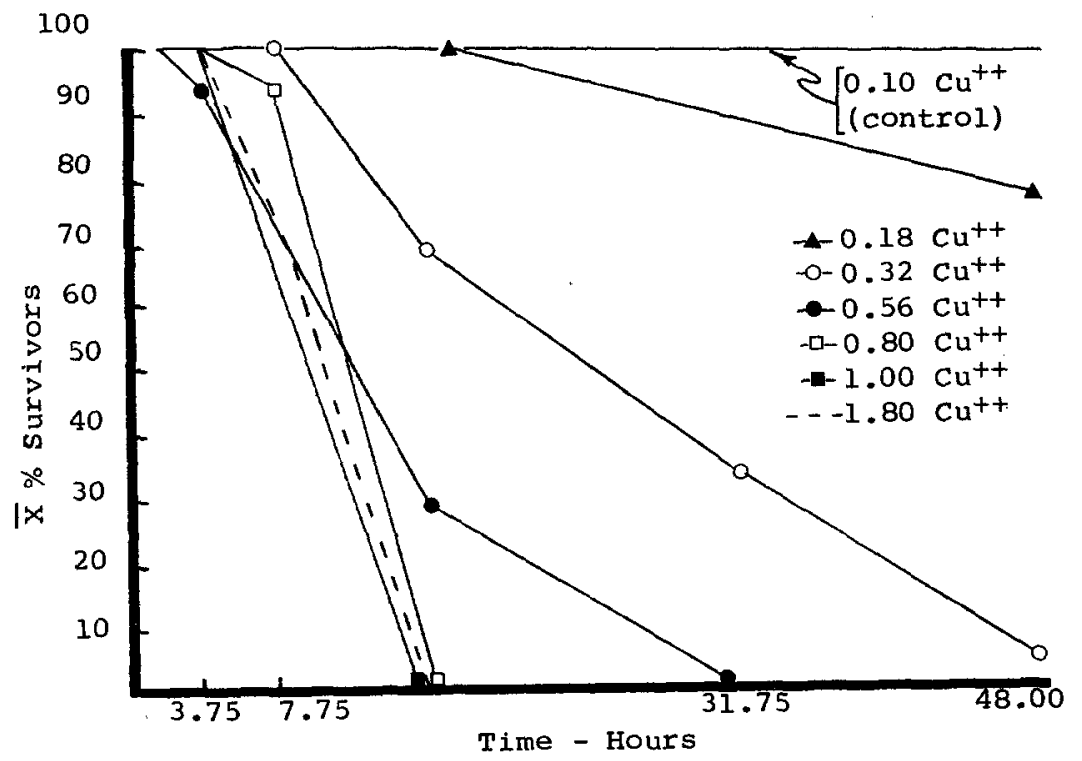

Fig. 2. Survivorship curves of $\mathrm{G}$. fasciatus in acute bioassays with $\mathrm{Cu}^{++}$ 
All tanks were cooled in a flow-through water bath with temperature maintained at 11.8 to $12.1^{\circ} \mathrm{C}$ throughout acclimation and testing. Well water from the University of Michigan Lakeside Laboratory was used as dilution water and cooling water. All battery jars were fully aerated for $24 \mathrm{hr}$ prior to testing to drive off $\mathrm{CO}_{2}$. Mean values for dissolved oxygen were maintained at $12.0 \mathrm{ppm}$ at $11.8^{\circ} \mathrm{C}$. (114\% of saturation). Aeration was continued throughout the test procedure as $\mathrm{Cu}++$ is a non-volatile material (STANDARD METHODS 1965).

Dissolved oxygen, hardness, and $\mathrm{pH}$ were determined at the beginning, middle, and end of the $48 \mathrm{hr}$ periods.. Mean $\mathrm{pH}$ values were 7.75 throughout the test and hardness, expressed as $\mathrm{mg} / \mathrm{L} \mathrm{CaCo}_{3}$, was 206. Lakeside laboratory water fits the definition of very hard water. Other characteristics of the well water are given in Table 1.

Table 1

\begin{tabular}{lll} 
& Well Water Data* & \\
\cline { 2 - 3 } & $\frac{\text { June }}{0.00}$ & July \\
$\mathrm{NO}_{3}-\mathrm{N}(\mathrm{ppm})$ & 702 & 0.00 \\
$\mathrm{NH}_{4}-\mathrm{N}(\mathrm{ppb})$ & 218 & 1700 \\
$\mathrm{PO}(\mathrm{ppb})$ & 347 & 204 \\
$\mathrm{Fe}(\mathrm{ppb})$ & 1.01 & 843 \\
$\mathrm{Cl}(\mathrm{ppm})$ & 2.8 & 1.53 \\
$\mathrm{Na}(\mathrm{ppm})$ & 0.5 & 2.6 \\
$\mathrm{~K}(\mathrm{ppm})$ & 13.0 & 0.7 \\
$\mathrm{Mg}(\mathrm{ppm})$ & 37.0 & 13.0 \\
$\mathrm{Ca}(\mathrm{ppm})$ & & 38.0 \\
$\mathrm{M}$ & &
\end{tabular}

*From Dr. John Gannon (1976), University of Michigan Biological Station, UnpubIished Data.

The organisms were selected randomly from a multiaged stock group and time till death was recorded at $0.25 \mathrm{hr}, 0.75 \mathrm{hr}, 1.75 \mathrm{hr}, 3.75 \mathrm{hr}, 7.75 \mathrm{hr}, 15.75 \mathrm{hr}$, $31.75 \mathrm{hr}$, and $48 \mathrm{hr}$. The number dead in each battery jar was recorded for the particular time and plotted on linear graph paper to determine death curves as percent survivors. These data were replotted on probit scale paper to give a straight line relationship and approximate LC50 values to use in the definitive tests. See Figure 1. Death was determined when the organism gave no response to a mechanical stimulus or showed no respiratory movement.

The LC50 value from the screening test was used as the middle concentration in the definitive test procedure. These values were: 


$$
\begin{gathered}
\mathrm{Cu+t} \text { as } \text { CuSo }_{4} \text {--Control, } 0.1,0.18,0.32,0.56, \\
0.80,1.0,1.8 \mathrm{ppm}^{-}
\end{gathered}
$$

Replicates were run simultaneously so that no variation occurred due to water chemistry, temperature fluctuation, or dissolved oxygen. The test times for death of the organisms were identical to those for the screening test, and the data were recorded similarly (See Figure 2).

The Litchfield and Wilcoxin Nomograph Analysis was used to determine the significance of lines drawn for best fit on a probit scale graph. The results of this analysis will be discussed later.

To ensure that no contamination occurred in any of the tanks, separate dip nets were used for the control groups and the Cut+ solutions. A stock solution of $100 \mathrm{ppm} \mathrm{Cu+t}$ was used to formulate dilutions. All chemicals were weighed.. on a Mettler Balance $\pm 0.1 \mathrm{mg}$ to insure accuracy. Dead organisms were remove $\bar{d}$ when visibly dead to insure no contamination due to metabolic waste products and oxidation.

\section{RESULTS}

Preliminary screening tests of G. fasciatus indicated good toxicity curves and response of the organism to Cut+. Preliminary values for Cu+t toxicity indicated a $48 \mathrm{hr}$ LC50 values of $0.19 \mathrm{ppm}$.

The definitive tests also gave good results. Mean Cu+t toxicity values were plotted for 2 consecutive runs of $48 \mathrm{hr}$ each as percent survivors against time with good curves resulting. These values were converted to percent dead after $48 \mathrm{hr}$ and plotted on 3 cycle probit paper to determine the definitive $48 \mathrm{hr}$ LC50. The value of $0.21 \mathrm{ppm}$ Cu+t was calculated as the concentration that killed $50 \%$ of the test organisms. The line was analyzed using the Litchfield and Wilgoxin Nomograph Analysis method for good fit, and a $x$ value of 1.16 was obtaine for the analysis with 1 degree of freedom. The table $x^{2}$ value was 3.41 so the line was not a bad fit. The Upper Limit of the LC50 value was $0.25 \mathrm{ppm}$; and the Lower Limit was $0.17 \mathrm{ppm}$. An analysis of the slope gave an $F$ value of 1.05 , with an Upper Limit on the slope sfope 1.50 and a Lower Limit of 1.36 . The toxicity of Cu+t at $0.21 \mathrm{ppm}, \alpha=.05$, was therefore significant (see Figure 3). 


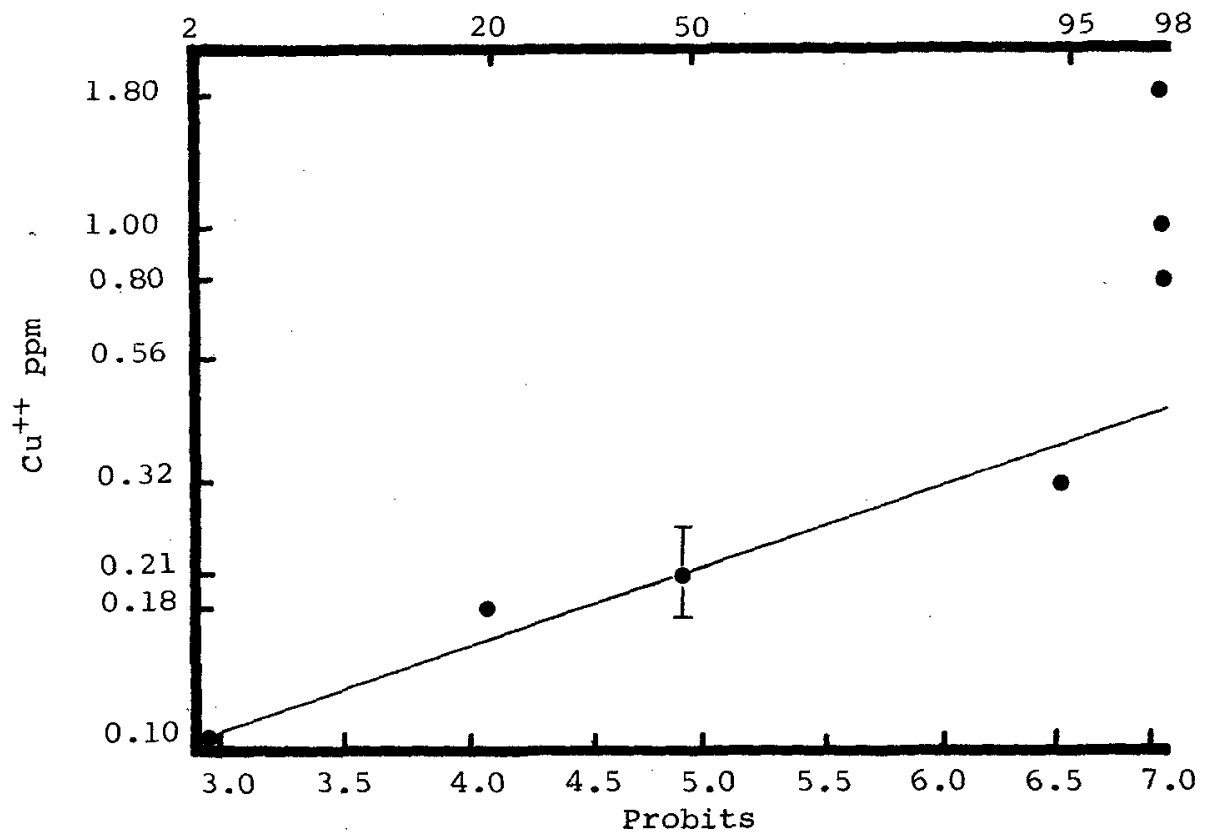

Fig. 3. Definitive LC50 Determination with $95 \%$ C.I.

\section{DISCUSSION}

The results of the $48 \mathrm{hr}$ acute bioassay for Cu+t were significant. The response of $G$. fasciatus to $\mathrm{Cu}++$ toxicity was reproducible. The results of the tests for Cu+t toxicity are also significant when compared with published values for Rainbow trout, Salmo gairaneri. HERBERT and VAN DYKE (1964) published data giving a $48 \mathrm{hr}$ LC50 value of $0.20 \mathrm{ppm}$ Cu+t for Rainbow trout in hard water. GECKLER et al. (1976) reported similar values of $0.15-0.20 \mathrm{ppm} \mathrm{Cu+t}(48 \mathrm{hr})$ in water with 125$175 \mathrm{mg} / \mathrm{L} \mathrm{CaCO}_{3}$ and a $\mathrm{pH}$ of 7.7 .

Since the results of the $48 \mathrm{hr}$ acute bioassay for $\mathrm{Cu}++$ on $G$. fasciatus are significant, $\alpha=.05$, it is reasonable to suggest that these organisms could be used as the experimental organism of importance in areas where they are found in abundance.

\section{CONCLUSIONS}

Gammarus fasciatus could, and possible should, be used as the experimental organism in conjunction with other organisms being used in laboratory bioassays. 
It is more economical to keep in the laboratory than Rainbow trout, Salmo gairdneri, and since experimental values for Cu+t toxicity are identical, or nearly so, it would seem to be a good practice. Admittedly, more tests need to be run with this organism to determine if its response to toxic compounds, on the whole, are comparable with results for other test organisms. Also, it should be determined if life stages influence toxicity results. G. fasciatus should be included in any bioassay program where they are an important aspect of the aquatic ecosystem under consideration.

\section{ACKNOWLEDGEMENTS}

I would Iike to thank especially Dr. John Cairns, Jr., for his invaluable advice during this experiment. Also, I would like to thank Dr. John E. Gannon for his help in obtaining a complete chemical analysis of the well water used during the experiment.

\section{REFERENCES}

GECKLER, J.R., W.B. Horning, T.M. Neiheisel, Q.H.

Pickering, E.L. Robinson and C.E. Stephan: The validity of laboratory tests for predicting copper toxicity in streams. EPA-600/3-76-116, December 1976.

HERBERT', D.W.M., and J.M. Van Dyke: Ann. of Appl. Biol. 53, $415(1964)$.

IITCHFIELD, J.T., Jr., and F. Wilcoxin: J. Pharmacol. Exp. Ther. 96, 99 (1949).

PATRICK, R., J. Cairns, Jr., and A. Scheier: Progr. Fish Cult. 30, 137 (1968).

PENNAK, R.W.: Fresh water invertebrates of the United States. New York: The Ronald Press Co. 1953.

Standard methods for the examination of water and wastewater. 12 ed. New York: APHA, AWWA, WPCF 1965. 